\title{
Nicolas SILD, Le Gallicanisme et la construction de l'État
} (1563-1905)

Clermont-Ferrand, Institut universitaire Varenne, 2016

\section{Olivier Saly-Rousset}

\section{(2) OpenEdition}

\section{Journals}

Édition électronique

URL : http://journals.openedition.org/rdr/367

DOI : $10.4000 /$ rdr.367

ISSN : 2534-7462

Éditeur

Presses universitaires de Strasbourg

Édition imprimée

Date de publication : 6 novembre 2018

Pagination : 187-188

ISBN : 979-10-344-0023-2

ISSN : 2493-8637

\section{Référence électronique}

Olivier Saly-Rousset, « Nicolas sıLD, Le Gallicanisme et la construction de l'État (1563-1905) », Revue du droit des religions [En ligne], 6 | 2018, mis en ligne le 25 novembre 2019, consulté le 19 novembre 2020. URL : http://journals.openedition.org/rdr/367 ; DOI : https://doi.org/10.4000/rdr.367

Ce document a été généré automatiquement le 19 novembre 2020. 


\title{
Nicolas SILD, Le Gallicanisme et la construction de l'État (1563-1905)
}

Clermont-Ferrand, Institut universitaire Varenne, 2016

\author{
Olivier Saly-Rousset
}

\section{RÉFÉRENCE}

Nicolas SILD, Le Gallicanisme et la construction de l'État (1563-1905), Clermont-Ferrand, Institut universitaire Varenne, 2016 (Collection des thèses), $582 \mathrm{p}$.

1 Apparu au début du XVI ${ }^{\mathrm{e}}$ siècle, mais explicitement nommé ainsi à la fin du XIxe siècle, le gallicanisme met en avant «l'idée d'un particularisme français au sein de l'universalité chrétienne » (p. 6). Il a été conçu pour tenter de résoudre les conflits susceptibles de survenir entre l'État et l'Église, l'institution ecclésiastique manifestant une autorité étrangère indépendante du fait de sa soumission au Vatican. Le discours gallican permettrait de faire coexister les deux puissances dans une conception duale tout en reconnaissant l'Église de France comme autonome face au Saint-Siège. En effet, l'ordre temporel (l'Église nationale) s'attacherait aux règles disciplinaires, tandis que l'ordre spirituel (l'Église universelle) se concentrerait sur les règles dogmatiques.

2 La situation est pourtant loin d'être aussi simple. Dans sa mission, l'Église catholique se voit dotée d'une fonction législative et réglementaire pour appliquer la discipline ecclésiastique. Elle est en mesure «d'édicter des prescriptions auxquelles les fidèles (laïcs ou clercs) sont soumis » (p. 43). Ses autorités ecclésiastiques possèdent aussi leurs propres juridictions qui sont situées au sein de l'État. À l'extérieur, le pape, les conciles et certaines congrégations romaines possèdent le pouvoir d'édicter des règles applicables dans les États. Ces éléments conduisent à considérer l'Église et l'État comme deux ordres juridiques qui peuvent entrer en contact. Il est possible de les voir « juxtaposés, coordonnés ou incorporés l'un à l'autre» (p. 25). La concurrence qui en découle crée des différends, à plus forte raison si certaines de ces règles doivent être intégrées dans l'ordre juridique étatique. Concentrant principalement son étude sur le 
gallicanisme parlementaire qui souhaite la déconfessionnalisation du pouvoir politique, Nicolas Sild montre comment le pouvoir politique s'est, grâce à lui, émancipé du pouvoir religieux.

3 La doctrine gallicane a représenté pour la chrétienté médiévale la fin de son unité et de son universalité. Elle a offert un support technique à la théorie de la souveraineté en supposant la séparation des ordres étatique et ecclésial. Cette logique a conduit à préserver l'État qui ne pouvait se plier à des dispositions étrangères. Les règles dogmatiques devenant des règles de droit commun, les intérêts de l'État étaient associés à ceux de l'Église de France, tandis que des mécanismes de vérification préalable étaient créés pour s'assurer de la compatibilité du droit ecclésiastique avec le droit français. Le système gallican « assure une fonction de protection de l'ordre public afin de prévenir les troubles à la tranquillité intérieure de l'État» (p.105) et une véritable police est mise en place pour s'assurer de la bonne application de la discipline ecclésiastique.

4 Au-delà, le consentement du souverain est nécessaire, ce qui «tend presque à substituer le pouvoir normatif du Souverain à celui du Pape» (p. 142). Le gallicanisme veille à ce que le roi détienne un monopole d'édiction du droit positif afin d'éviter au royaume l'invasion des règles ecclésiastiques, sachant que le roi souverain se limite de lui-même par sa conscience religieuse. À cette fin, un recours sera institué contre les décisions des autorités religieuses : l'appel comme d'abus. Celui-ci « aura eu pour effet de hisser les lois de l'État au-dessus des autorités ecclésiastiques, en les intégrant dans une hiérarchie embryonnaire » (p. 518). La juridiction d'Église va progressivement être subordonnée aux prérogatives de la puissance publique. Au final, cette dynamique gallicane aura consisté «à vider la puissance ecclésiastique de ses prérogatives temporelles en armant ses sujets contre elle» (p.462) et aura permis au pouvoir étatique de créer un ordre juridique à partir d'une souveraineté élaborée abstraitement et techniquement.

\section{AUTEURS}

\section{OLIVIER SALY-ROUSSET}

Vacataire en droit public, Université de Perpignan Via Domitia, Centre du droit économique et du développement (CDED) 